\title{
EDITORIAL
}

\section{Gênero e diversidade sexual na escola: a urgência da reconstrução de sentidos e de práticas}

O debate sobre a inserção da temática "Gênero e diversidade sexual" na escola tem sido construído com grande esforço em nosso país por grupos organizados, educadores, pesquisadores e poder público, e se materializado em pesquisas, em artigos, eventos, em ações educativas e em documentos oficiais.

Freire, Haddad e Ribeiro (2007, p. 15) referem-se à construção de uma política pública de educação em gênero e diversidade reconhecendo que não "[...] bastarão leis, se não houver a transformação de mentalidades e práticas". Mentalidades estas que compreendem a diversidade sexual como algo patológico e alinham sexo, gênero e sexualidade, associando gênero à constituição biológica de macho e fêmea. Práticas que negligenciam a sexualidade em sua dimensão histórica e social e (re)produzem preconceitos, discriminação, marginalização e exclusão. Mentalidades e práticas construídas historicamente, influenciadas pela política, pela economia, pela religião, entre outros determinantes.

A reflexão sobre mentalidades e práticas em relação à sexualidade, gênero e diversidade sexual nos remete aos conceitos de significado, sentido e prática social. Significados construídos, compartilhados e cristalizados historicamente que, apropriados pelos indivíduos, tornam-se sentidos (subjetivação de significados) e, articulados, sustentam a abordagem dessa temática nas escolas: disciplinar, normativa e reducionista.

Após quase vinte anos da publicação dos Parâmetros Curriculares Nacionais (BRASIL, 1997) que propôs a transversalização da temática sexualidade na escola (chamada de orientação sexual), pode-se afirmar que essa proposta não se efetivou, por razões diversas, dentre as quais destacamos desconhecimento e despreparo em relação ao tema e à abordagem transversal. Com um maior rigor na análise pode-se, mesmo, questionar se essa temática é abordada efetivamente nas escolas e reconhecer que não há consensos sobre o que abordar, como abordar e quem abordar.

Estudo realizado por Lira e Jofili (2010) constatou que professores desconheciam a proposta de tema transversal para a temática sexualidade e outros estudos relatam a falta de preparo e a insegurança de professores na abordagem do tema.

Nesse cenário, perpetua-se uma prática historicamente construída: a abordagem de aspectos biológicos da sexualidade (aparelho reprodutor, reprodução, doenças sexualmente transmissíveis e métodos contraceptivos) pelo professor da área de Ciências, mantendo-se o "currículo sexual oculto" que "ensina a normalização das expressões de gênero, o modelo do casal heterossexual reprodutor, a família nuclear, a hierarquização dos gêneros, a exclusão de orientações sexuais diferentes etc." (BARRETO; ARAÚJO; PEREIRA, 2009, p. 180), contribuindo-se para a reprodução de preconceitos e discriminações em relação à sexualidade e à diversidade sexual. 
Assim, este mesmo cenário traz a possibilidade de transformações: a revisão e a alteração de sentidos sobre sexualidade, gênero e diversidade sexual de professores da área de Ciências e de suas práticas educativas.

A sexualidade humana não se restringe a um corpo que possibilita reprodução, que engravida, que adoece e que se previne. É uma construção pessoal/social que se forma ao longo da vida, num processo contínuo e complexo, que articula aspectos biológicos/fisiológicos, psicológicos, sociais, culturais e históricos, e que pode ser vivenciada a partir de diferentes possibilidades em relação às orientações sexuais (hétero, homo e bissexualidade) e às identidades de gênero (percepção subjetiva de ser masculino ou feminino, conforme o convencionalmente estabelecido).

Sexo e gênero são componentes da sexualidade, sendo que gênero se refere à construção social do sexo anatômico, distinguindo-se, assim, a dimensão biológica da social. Se ser macho ou fêmea é determinado pela anatomia, a maneira de ser homem e de ser mulher é resultado da cultura, da realidade social.

Nesse sentido, como alertado é preciso distinguir entre:

1. corpos, capacidades reprodutivas, diferenças fisiológicas entre homens e mulheres;

2. modos de ser masculino e feminino, senso de pertencer a um ou a outro gênero;

3. focos de sentimentos, atração, desejo e fantasias, apegos emocionais, vínculos interpessoais, relacionamentos fundamentais. (BARRETO; ARAÚJO; PEREIRA, 2009, p. 118)

Abordagens reducionistas sobre o tema sexualidade na escola não fazem esta distinção, naturalizando questões sociais, impondo padrões e dificultando a problematização dos preconceitos e o respeito à diversidade sexual.

A escola é espaço de formação humana, de humanização, pela transmissão/apropriação de conhecimentos científicos, filosóficos e artísticos, possibilitando a compreensão e a transformação da realidade.

A abordagem de sexualidade, gênero e diversidade sexual na escola precisa contribuir para esse processo de humanização, sendo fundamental "romper ideias cristalizadas e construídas na sociedade, formando um ser humano consciente das relações sociais a que está submetido, principalmente considerando esse ser humano no período da adolescência" (MAIA et al., 2012, p. 152).

A defesa não é pela abordagem da sexualidade unicamente pelos professores de Ciências, mesmo com a superação da visão biologizante, mas pelo reconhecimento de que o espaço atualmente ocupado por esta área na abordagem dessa temática pode e deve se tornar espaço de problematização de significados e sentidos heteronormativos e preconceituosos.

Coloca-se, assim, uma questão premente ao ensino e à pesquisa em ensino de Ciências: o reconhecimento de significados e sentidos que sustentam a abordagem da temática sexualidade e a elaboração de novos sentidos que se incorporem às discussões de gênero e diversidade sexual.

Em relação à produção científica sobre as temáticas sexualidade e gênero no Brasil, Pereira e Monteiro (2013) analisaram periódicos da área de Ensino na base de dados Scielo, no período de 2006 a 2011. Identificaram 112 artigos, sendo que 52 estavam diretamente relacionados ao Ensino/Educação, tendo como principais temas as práticas educativas, a análise de políticas públicas e/ou produção acadêmica, características/concepções de professores e 
alunos, e gênero e educação. Pode-se verificar, ainda, que, do total de 112 periódicos diretamente relacionados ao ensino de Ciências, em cinco foram publicados 14 artigos nesse período.

Em levantamento realizado nos trabalhos apresentados no VIII e no IX Encontro Nacional de Pesquisa em Educação em Ciências, realizados respectivamente em 2011 e 2013, utilizando-se como descritor os termos sexualidade e gênero foram identificados 35 trabalhos (num total de 2.295 trabalhos selecionados nas duas edições, sendo 19 em 2011 e 16 em 2013). Deste total, em 16 deles a palavra gênero foi indicada como uma das palavras-chave.

Estes dados sugerem uma aproximação, embora tímida, da área com a temática. Analisar dados de pesquisa na área de Psicologia, Sociologia, dentre outras das Ciências Humanas e Sociais, que denunciam diferentes formas de acobertamento e o não enfrentamento de preconceitos e discriminações na escola, e produzir conhecimentos nessa área são tarefas urgentes de educadores e pesquisadores na área de Ciências.

Não bastam somente leis para que sentidos e práticas educativas sejam reconstruídas. É preciso, também, que pesquisadores da área de ensino de Ciências reflitam sobre a temática e que resultados de pesquisas fundamentem as discussões em torno do tema.

Luciana Maria Lunardi Campos

Departamento de Educação, Instituto de Biociências, Universidade Estadual Paulista (UNESP), Rua Cecília Magaldi, s/n, CEP 18618-697, Botucatu, SP, Brasil. E-mail: <camposml@ibb.unesp.br>

\section{Referências}

BARRETO, A.; ARAÚJO, L.; PEREIRA, M. E. (Org.). Gênero e diversidade na escola: formação de professoras/es em gênero, orientação sexual e relações étnico-raciais - livro de conteúdo. Rio de Janeiro: CEPESC; Brasília: SPM, 2009. Disponível em: <http:// estatico.cnpq.br/portal/premios/2014/ig/pdf/genero_diversidade_ escola_2009.pdf>. Acesso em: 6 out. 2015.

BRASIL. Ministério da Educação e do Desporto. Secretaria de Educação Fundamental. Parâmetros curriculares nacionais: orientação sexual. Brasília, 1997. 
FREIRE, N.; HADDAD, F.; RIBEIRO, M. Construindo uma política de educação em gênero e diversidade. In: PEREIRA, M. E. et al. (Org.). Gênero e diversidade na escola: formação de professoras/es em gênero, sexualidade, orientação sexual e relações étnico-raciais. Rio de Janeiro: CEPESC, 2007. p. 15-16. Disponível em: <http://www.spm.gov.br/central-de-conteudos/publicacoes/ publicacoes/2007/gde-2007.pdf>. Acesso em: 6 out. 2015.

LIRA, A.; JOFILI, Z. O tema transversal orientação sexual nos PCN e a atitude dos professores: convergentes ou divergentes?

Ensino, Saúde e Ambiente, Niteroi, v. 3, n. 1, p. 22-41, 2010. Disponivel em: <http://www.ensinosaudeambiente.uff.br/index. php/ensinosaudeambiente/article/view/105/104>. Acesso em: 15 jan. 2015.

MAIA, A. C. B. et al. Educação sexual na escola a partir da psicologia histórico-cultural. Psicologia em Estudo, Maringá, v. 17, n. 1, p. 151-156, jan./mar. 2012. Disponível em: < http://dx.doi. org/10.1590/S1413-73722012000100017>. Acesso em: 12 jun. 2014.

PEREIRA, M. E.; BRANDT, M. E. A efetivação de parcerias necessárias à construção de uma política de educação em gênero e diversidade. In: PEREIRA, M. E. et al. (Org.). Gênero e

diversidade na escola: formação de professoras/es em gênero, sexualidade, orientação sexual e relações étnico-raciais. Rio de Janeiro: CEPESC, 2007. p. 19-24. Disponível em: < http://www. spm.gov.br/central-de-conteudos/publicacoes/publicacoes/2007/ gde-2007.pdf>. Acesso em: 6 out. 2015.

PEREIRA, Z. M.; MONTEIRO, S. Gênero e sexualidade no ensino de ciências no Brasil: análise da produção científica recente. In: IX ENCONTRO NACIONAL DE PESQUISA EM EDUCAÇÃO EM CIÊNCIAS, 9., 2013, Águas de Lindoia. Atas... Disponível em: <http://www.nutes.ufrj.br/abrapec/ixenpec/atas/resumos/ R0919-1.pdf>. Acesso em: 15 jan. 2015. 